\title{
Urethral Infection, CTCAE
}

National Cancer Institute

\section{Source}

National Cancer Institute. Urethral Infection, CT CAE. NCI Thesaurus. Code C143899.

A disorder characterized by an infectious process involving the urethra. 